\title{
Influence of Sex Education on Abortion Prevention among Adolescents in High Level, Makurdi Local Government Area of Benue State
}

\author{
Dzer, Benjamin Terzungwe $\mathrm{PhD}^{1^{*}}$, Igomu Maria Oojo N's ${ }^{2}$, Onuh, Onuh Emmanuel ${ }^{3}$ \\ ${ }^{1,2}$ Department of Nursing College of Health Sciences Benue State University, Makurdi, Nigeria \\ ${ }^{3}$ Department of Clinical Psychology, Federal Medical Center, Makurdi, Benue State, Nigeria \\ *Corresponding Author
}

\begin{abstract}
This study was conducted to find out the influence of sex education on abortion prevention among adolescents in High Level, Makurdi Local Government Area of Benue State. The objectives of the study were, to identify the major factors responsible for lack of sex education among adolescents, to identify the various means of carrying out sex education among adolescents, to identify if adolescents have the right information about sex and sexuality, to identify the influence of sex education on abortion prevention among adolescents. Related literatures were reviewed. A descriptive research design was used to study 100 respondents which were selected from a target population of 200 adolescents. A simple random sampling technique was employed. The instrument used for data collection was a selfconstructed Sex Education questionnaire (SEQ) and Abortion Prevention questionnaire (APQ). The results were analyzed and presented using tables. Findings of the study showed that, family settings, schools, culture, peers, mass media are some of the major factors responsible for lack of appropriate sex education among adolescents in High Level, Makurdi. Parents/guardians, schools/teachers, peers/friends, religious bodies are some of the means of carrying out sex education among adolescents. Some of the influence of appropriate sex education includes, abortion prevention, reduction in the rate of teenage/adolescent pregnancy and adolescent fatherhood, prevention of STIs including HIV/AIDs etc. Based on these findings major recommendations are that the government should create and fund effective sex education programs, seminars and sex education should be included in secondary school curriculum.
\end{abstract}

Key Words: Sex, Education and Adolescents.

\section{INTRODUCTION}

$\mathrm{H}$ uman beings are a class of primates who are known as 'Homosapiens' 'meaning the modern man' or the wise man with highest capacity among all creatures. That is why human beings are the most civilized of all living things on earth (Olayinka, 2011).

In contrast to other primates, human sexual behavior is strongly determined especially in adolescents. Early initiation of sexual intercourse and little or no sex education are key indications of adolescent's potential risk for unplanned pregnancy and abortion. (Olayinka, 2011).

Sex education is defined as, learning about the cognitive, emotional, social, interactive and physical aspects of sexuality. Sexuality education starts early in childhood and progresses through adolescence and adulthood. It aims at supporting and protecting sexual development. It gradually equips and empowers children and young people with information, skills and positive values to understand and enjoy their sexuality, have safe and fulfilling relationships and wellbeing (World Health Organization, 2010). WHO (2011), coined that, adolescents are those people between 10-19 years of age. That great majority of adolescents are therefore, included in the age-based definition of "Child" adopted by the convention on the rights of the child, as a person under the age of 18-19 years.

The period of adolescence occupies a unique stage in every person's life. "Adolescence" is a dynamically evolving theoretical construct informed through physiologic, psychosocial, temporal and cultural lenses. This critical developmental period is conventionally understood as the years between the onset of puberty and the establishment of social independence (Steinberg, 2014).

Adolescences are a distinct phase of the developmental life cycle in humans and other animal's species (Elliot \& Feldman, 2013; Spear, 2014). Among humans, adolescence is a complex, multi-system transitional process involving progression from the immaturity and social dependency of childhood into adult life with the goal and expectation of fulfilled developmental potential, personal agency and social accountability (Green field, Keller \& Maynard, 2015). According to Graber (2016), development transitions occurring during adolescences require reciprocal reorganization of the individual and the context influencing cognition, emotion, behavior and relationships.

Many adolescents manages this transformation successfully while others experience major stresses and find themselves engaging in sexual behaviors and developmental characteristics that place them at unintended consequence such as unwanted pregnancy which might lead to abortion and also sexually transmitted infections (STIs). By the age of 18years, most adolescents in Nigeria are poor contraceptive users. They are less likely than adults to consistently use condoms or other methods of protection that could reduce 
their chances of the risks association with sexual intercourse especially abortion, HIV and other STIs. (Graber, 2016).

Sex education prevents the high rate of abortion. According to the statistics from Planned Parenthood Federation of America PPFA (2012), adolescents are more sexually active now than before "twenty-five percent of all girls and thirty-three percent of all boys have had sex by the age seventeen, the statistics have grown to seventy-five percent of all girls and eighty-six percent of all boys" (Anonymous, 2012). The same unbelievable information was researched by institution of pollution and family pointed that the abortion rate of young women (from age of 15-19) approximately 30 percent on overall, ranked $5^{\text {th }}$ in the world (Giatminh, 2012). Potentially, schools, parents and religious bodies provide a key opportunity to reach large numbers of young people with sex relationships and HIV education. Sex education enables adolescents to have and acquire the knowledge associated with sex, sexuality, use of contraceptives, damage and risks associated with sexual intercourse such as unwanted pregnancy and consequently abortion. Proper and adequate sex education prevents adolescents from getting information from the wrong sources and experimenting as they tend to be very inquisitive at this stage. (Giatminh, 2012).

Approved sex education at high school is a way to protect our future generation. Hoai (2012), Stated that some opposition view argued that in teaching sex education we somehow bring grist to children's hands. However, psychologist Hong Ngoc Do said that the misunderstanding of our education system is passive-psychological and to entrust for school and scare of being naughty. We get better off giving instruction to have right path than let them mislead.

\section{STATEMENT OF THE PROBLEM}

Adolescents ignorantly indulge in sexual activities due to improper awareness of sex education. The incidence of abortion which is more prevalent amongst adolescents due to poor sex education is a source of concern to the public which have necessitated the need for sexual education. Parents however, have neglected their roles in terms of sex education of the adolescent with the expression that it leads to curiosity and experimentation. Empirical evidence and records from Federal Medical Centre, Makurdi have shown that most of the people that present with case of abortion are youths especially girls between the age of 12-18 years.

Also, further investigation in High Level, Makurdi which is the area under study indicates a high percentage of adolescents have had abortion or other negative health impact at one point in time. On this note, the researcher wants to find out influence of sex education on abortion prevention.

\section{Objectives of the Study}

i. To investigate the major factors responsible for lack of sex education among adolescents

ii. To ascertain the various means of carrying out sex education among adolescents iii. To investigate if adolescents have the right information about sex and sexuality.

iv. To ascertain the influence of sex education on abortion prevention among adolescents.

\section{Research Questions}

i. What are the major factors responsible for lack of sex education among adolescents?

ii. What are the various means of carrying out sex education among adolescents?

iii. Do adolescent have the right information about sex and sexuality?

iv. What is the influence of sex education on abortion prevention among adolescents?

\section{METHODOLOGY}

This is a descriptive and non-experimental research it is designed to look into the influence of sex education on abortion prevention among adolescents in High Level, Makurid Local Government Area of Benue State.

\section{Settings}

This study was carried out in High level, Makurdi Local Government Area of Benue State. Benue State was created from Benue-plateau in 1976. Makurdi has two (2) main districts which are, the South bank and the North bank. Makurdi Local Government Area has a vast and fertile land across the regions, the land is largely populated and inhibited by the Tiv, Idoma, Igede, Itilo, Jukun, Hausa and other ethnic groups. Makurdi has an estimated population of five hundred thousand, seven hundred and ninety seven (500, 797) (National) population census, 2006). Some of the inhabitants of this geographical area are mostly farmers while others who reside around the river banks are fishermen. There are also traders, civil servants and settlers from other states of the federation.

The region has the second biggest recognized river in Nigeriathe River Benue, which has its source from the Cameroon border basin and passes through to the River Niger in Kogi state, North-central Nigeria. There are many private clinics in this region with a general Hospital at North Bank, Federal Medical Center, Family support programme clinic/maternity home and a Teaching Hospital in the Benue State University. In terms of education, there are over 60 primary and secondary schools and two universities which are the Benue State University and Federal University of Agriculture within the state capital.

Owing to its location in the valley of the River Benue, makurdi experience warm temperatures most of the years but when the harmattan and rain seasons set in, the temperature is relatively cold. High level was chosen to aid the successful accomplishment of this research work in terms of data collection. 


\section{Target Population}

The target population of this research work comprises of 200 adolescents age 13-19 years in High level Makurdi. Male and female adolescents were randomly selected.

\section{Sample and Sampling Technique}

A simple random sampling technique was used in this research work to ensure that there is an even representation of the population of High level, Makurdi Local Government Area. Each sample unit was given an equal chance of being selected. A sample size of 100 adolescents was drawn out of the target population of 200 adolescents.

\section{Sample Size Determination}

A sample frame of 200 populations $50 \%$ of the population was used to minimize sampling error.

$$
\begin{aligned}
& \text { Sampling Size }=\frac{50}{100} \times \frac{200}{1}=100 \\
& \text { Sample Size }=100
\end{aligned}
$$

Therefore, the sample size of the population is 100

\section{Instrument of Data Collection}

The major instrument used in collecting data for this research work was questionnaire. Questionnaires containing 20 question were designed into section $\mathrm{A}$ and $\mathrm{B}$. section $\mathrm{A}$ contained the personal data of the respondents while section B contained relevant data in relation to the topic of study. All the questions were closed ended.

\section{Validity and Reliability of Instrument.}

Copies of the self-constructed Sex Education questionnaire (SEQ) and Abortion Prevention questionnaire (APQ) were given to academic lecturers for vetting, critique and suggestions were implemented before administration. This is to ensure that questionnaire measures what it is supposed to measure. The same questionnaires were pre-tested on a small population of thirty (30) of the study group before the final administration to 100 respondents. The questionnaires produced similar results under consistent condition.

\section{METHOD OF DATA COLLECTION}

Data were collected from primary sources. The primary source of information involves the use of questionnaires. A 20 -item questionnaire was printed and 100 copies were distributed to 100 respondents in High level. Specific time was allowed for clarification and filling after which the questionnaires were retrieved the same day. There was no casualty of questionnaire; the researcher adhered strictly to the ethical codes of conduct acting in strict confidence to the respondents as regards the information obtained from the data. Their responses were handled confidentially giving the necessary respect to them with all anonymity and privacy as due. They consented and participated voluntarily.
Falsification of data and plagiarism were completely avoided as the researcher obtained firsthand information through questionnaires and face to face interactions. All bias was avoided to enable the researcher get accurate result free from manipulative vices. All the respondents were given due respect and fair treatment. The respondents were duly appreciated verbally.

\section{RESULTS}

\section{Data Presentation and Analysis}

Section A: Demographic data

Table 1: Showing the sex of respondents

\begin{tabular}{|c|c|c|}
\hline Sex of respondents & Frequency & Percentage (\%) \\
\hline Male & 32 & 32 \\
\hline \hline Female & 68 & 68 \\
\hline Total & 100 & 100 \\
\hline
\end{tabular}

Source: field survey, 2020

The table above shows that out of $100(100 \%)$ respondents, $32(32 \%)$ of respondents were males whereas the remaining $68(68 \%)$ of respondents were females.

Table 2: Showing the age of respondents

\begin{tabular}{|c|c|c|}
\hline Age & Frequency & Percentage $(\%)$ \\
\hline $13-14$ & 21 & 21 \\
\hline $15-16$ & 35 & 35 \\
\hline $17-19$ & 44 & 44 \\
\hline \hline Total & 100 & 100 \\
\hline
\end{tabular}

Source: Field survey, 2020

The table 2 above shows that, out of the $100(100 \%)$ respondents,21( $21 \%$ ) of respondents were 13-14 years, $35(35 \%)$ of respondents were $15-16$ years while $44(44 \%)$ respondent were 17-19 years.

Table 3 showing the educational level of respondents

\begin{tabular}{|c|c|c|}
\hline Educational level & Frequency & Percentage (\%) \\
\hline \hline Primary & 11 & 11 \\
\hline Secondary school & 65 & 65 \\
\hline \hline Tertiary & 24 & 24 \\
\hline Total & 100 & 100 \\
\hline
\end{tabular}

Source: Field survey, 2020

The above table 3 shows that, out of the 100(100\%) respondents, 11(11\%) of respondents were in primary school, $65(65 \%)$ of respondents were in secondary school while $24(24 \%)$ of respondents were in tertiary. 
Table 4: Showing the religion of respondents

\begin{tabular}{|c|c|c|}
\hline Religion & Frequency & Percentage (\%) \\
\hline \hline Christian & 83 & 83 \\
\hline \hline Muslim & 17 & 17 \\
\hline \hline Pagan & 0 & 0 \\
\hline Total & 100 & 100 \\
\hline
\end{tabular}

Source: Field Survey, 2020

The above table 4 shows that out of $100(100 \%)$ respondents, $83(83 \%)$ of respondents were Christians, $17(17 \%)$ of respondents were Muslims while $0(0 \%)$ of respondents were pagans.

Table 5: Showing the marital status of respondents

\begin{tabular}{|c|c|c|}
\hline Marital status & Frequency & Percentage (\%) \\
\hline \hline Single & 97 & 97 \\
\hline Married & 3 & 3 \\
\hline \hline Divorced & - & - \\
\hline Total & 100 & 100 \\
\hline
\end{tabular}

Source: Field survey, 2020

The table 5 shows that out of $100(100 \%)$ of respondents, $97(97 \%)$ of respondents were single, 3 (3\%) of respondents were married while none of the respondents were divorced.

Table 6: Showing responses to knowledge of sex education

\begin{tabular}{|c|c|c|}
\hline Knowledge & Frequency & Percentage (\%) \\
\hline \hline Yes & 92 & 92 \\
\hline \hline No & 8 & 8 \\
\hline \hline Total & 100 & 100 \\
\hline
\end{tabular}

Source: Field survey, 2020

The above table shows that out of $100(100 \%)$ of respondent, $92(92 \%)$ of respondents said they have heard about sex education while $8(8 \%)$ of respondents said they have not heard about sex education.

Table 7: Showing responses to what sex education is.

\begin{tabular}{|c|c|c|}
\hline Sex education & Frequency & Percentage (\%) \\
\hline \hline $\begin{array}{c}\text { Teaching children on how to have } \\
\text { sex }\end{array}$ & 5 & 5 \\
\hline $\begin{array}{c}\text { Providing information to adolescents } \\
\text { on how to prevent STIs }\end{array}$ & 20 & 20 \\
\hline \hline $\begin{array}{c}\text { Providing information to adolescents } \\
\text { on how to prevent pregnancy }\end{array}$ & 10 & 63 \\
\hline $\begin{array}{c}\text { To provide information to adolescent } \\
\text { about sexual matters in order to } \\
\text { impact knowledge in them for better } \\
\text { understanding }\end{array}$ & 100 & 100 \\
\hline \hline Total & & \\
\hline
\end{tabular}

Source: Field survey, 2020

The above table shows that, out of $100(100 \%)$ of respondents, 5 (5)\% of the respondents said sex education teaches children on how to have sex, 20(20\%) of respondents said sex education is providing information to adolescents on how to prevent STIs,10(10\%) of respondents said sex education is providing information to adolescents on how to prevent pregnancy while 65(65\%) of respondents said sex education is to provide information to adolescents about sexual matters in order to impact knowledge in them for better understanding.

Table 8: Showing responses of respondents on sex education

\begin{tabular}{|c|c|c|}
\hline Sex educator & Frequency & Percentage (\%) \\
\hline \hline Parents/guardians & 17 & 17 \\
\hline School/teachers & 18 & 18 \\
\hline Pees/friends & 25 & 25 \\
\hline \hline Religious bodies & 10 & 10 \\
\hline Mass media/internet & 30 & 30 \\
\hline Total & 100 & 100 \\
\hline
\end{tabular}

Source: Field survey, 2020

The above table shows that, out of $100(100 \%)$ respondents, $17(17 \%)$ of respondents said they were sex educated by parents/guardians, $18(18 \%)$ of respondents said they were sex educated by school/teachers, $25(25 \%)$ of respondents said they were sex educated by peers/friends,10(10\%) of respondents said they were sex educated by religious bodies while $30(30 \%)$ of respondents said were sex educated by mass media/internet.

Table 9: Showing responses if respondents have ever had sex

\begin{tabular}{|c|c|c|}
\hline Ever had sex & Frequency & Percentage (\%) \\
\hline \hline Yes & 3 & 3 \\
\hline \hline No & 97 & 97 \\
\hline \hline Total & 100 & 100 \\
\hline
\end{tabular}

Source: Field survey, 2020

The above table shows that, out of $100(100 \%)$ of respondents, $3(3 \%)$ of respondents have had sex while $97(97 \%)$ of respondents have never had sex.

Table 10: Showing responses of what sex is

\begin{tabular}{|c|c|c|}
\hline Sex & Frequency & Percentage (\%) \\
\hline \hline $\begin{array}{c}\text { Playing with the opposite } \\
\text { gender }\end{array}$ & 5 & 5 \\
\hline $\begin{array}{c}\text { Touching the opposite } \\
\text { gender's reproductive organs }\end{array}$ & 5 & 5 \\
\hline $\begin{array}{c}\text { Talking to the opposite } \\
\text { gender }\end{array}$ & 5 & 75 \\
\hline $\begin{array}{c}\text { Penetration of the vagina by } \\
\text { the penis }\end{array}$ & 75 & 100 \\
\hline \hline Total & 100 & \\
\hline
\end{tabular}

Source: Field survey, 2020

The above table shows that, out 100(100\%) respondents,5 ( $5 \%$ ) of respondents said sex is playing with the opposite gender, $5(5 \%)$ of respondents said sex is touching the opposite 
gender's genitalia, $5(5 \%)$ of respondents said sex is talking to the opposite gender while $75(75 \%)$ of respondents said sex is the penetration of the vagina by the penis.

Table 11: Showing responses of what abortion is

\begin{tabular}{|c|c|c|}
\hline Abortion & Frequency & Percentage (\%) \\
\hline \hline $\begin{array}{c}\text { The interruption of pregnancy } \\
\text { before the time of delivery }\end{array}$ & 81 & 81 \\
\hline \hline Flushing of pregnancy & 10 & 10 \\
\hline \hline $\begin{array}{c}\text { Taking of potash to flush } \\
\text { pregnancy }\end{array}$ & 2 & 2 \\
\hline \hline Removal of pregnancy & 7 & 7 \\
\hline \hline Total & 100 & 100 \\
\hline
\end{tabular}

Source: Field survey, 2020

The above table shows that, out of $100(100 \%)$ respondents, $81(81 \%)$ of respondents said abortion is the interruption of pregnancy before the time delivery, $10(10 \%)$ of respondents said abortion is flushing of pregnancy, 2 ( $2 \%$ ) of respondents said abortion is the taking of potash to flush pregnancy while $7(7 \%)$ of respondents said abortion is the removal of pregnancy.

Table 12: Showing responses if sexual intercourse exposes one to sexual problem

\begin{tabular}{|c|c|c|}
\hline $\begin{array}{c}\text { Sexual intercourse and sexual } \\
\text { problem }\end{array}$ & Frequency & Percentage (\%) \\
\hline \hline Yes & 98 & 98 \\
\hline \hline No & 2 & 2 \\
\hline \hline Total & 100 & 100 \\
\hline
\end{tabular}

Source: Field survey, 2020

The above table shows that, out of 100 (100\%) respondents, $98(98 \%)$ of respondents said sexual intercourses exposes one to sexual problem while $2(2 \%)$ of respondents said sexual intercourse does not exposes one to sexual problems.

Table 13: Showing responses of some of the sexual problem encountered by adolescents.

\begin{tabular}{|c|c|c|}
\hline Sexual problem & Frequency & Percentage (\%) \\
\hline \hline $\begin{array}{c}\text { Teenage pregnancy and } \\
\text { adolescent fatherhood }\end{array}$ & 11 & 11 \\
\hline \hline STIs & 8 & 8 \\
\hline \hline Abortion & 1 & 1 \\
\hline \hline All of the above & 80 & 80 \\
\hline Total & 100 & 100 \\
\hline
\end{tabular}

Source: Field survey, 2020

The table above shows that, out of 100 (100\%) respondents, $11(11 \%)$ of respondents said some of the sexual problem encountered by adolescents are teenage pregnancy and adolescent fatherhood, $8(8 \%)$ of respondents said STIs, 1(1\%) of respondents said Abortion while $80(80 \%)$ of respondents said all of the above.
Table 14: Showing response of ways adolescents can prevent sexual problems.

\begin{tabular}{|c|c|c|}
\hline $\begin{array}{c}\text { Ways of preventing sexual } \\
\text { problems }\end{array}$ & Frequency & Percentage (\%) \\
\hline $\begin{array}{c}\text { Not engaging in illicit sexual } \\
\text { activities }\end{array}$ & 11 & 11 \\
\hline Not engaging in criminal abortion & 8 & 8 \\
\hline Proper health education & 60 & 60 \\
\hline All of the above & 22 & 22 \\
\hline Total & 100 & 100 \\
\hline
\end{tabular}

Source: Field survey, 2020

The table above shows that, out of $100(100 \%)$ respondents, $11(11 \%)$ of respondents said not engaging in illicit sexual activities are ways adolescents can prevent sexual problems, $8(8 \%)$ of respondents said not engaging in criminal abortion, $60(60 \%)$ of respondents said proper health education while $22(22 \%)$ of respondents said all of the above.

Table 15: Showing responses of knowledge of factors responsible for lack of sex education

\begin{tabular}{|c|c|c|}
\hline $\begin{array}{c}\text { Knowledge of factors } \\
\text { responsible for lack of sexual } \\
\text { education }\end{array}$ & Frequency & Percentage (\%) \\
\hline Yes & 82 & 82 \\
\hline No & 18 & 18 \\
\hline Total & 100 & 100 \\
\hline
\end{tabular}

Source: Field survey 2020

The table above shows that, out of $100(100 \%)$ respondents, $82(82 \%)$ of respondents said they have knowledge of factors responsible for lack of sex education while 18(18\%) of respondents said they have no knowledge of the factors responsible for lack of sex education.

Table 16: Showing responses of respondents of factors responsible for lack of sex education they are aware of

\begin{tabular}{|c|c|c|}
\hline $\begin{array}{c}\text { Factors responsible for lack of } \\
\text { sex education }\end{array}$ & Frequency & Percentage (\%) \\
\hline Family setting & 50 & 50 \\
\hline School & 3 & 3 \\
\hline Culture & 15 & 15 \\
\hline Peer pressure & 5 & 5 \\
\hline Mass media & 5 & 5 \\
\hline All of the above & 22 & 22 \\
\hline Total & 100 & 100 \\
\hline
\end{tabular}

Source: Field survey, 2020

The above table shows that, out of $100(100 \%)$ respondents, $50(50 \%)$ of respondents said family settings is the factor responsible for lack of sex education they are aware of, 3(3\%) of respondents said school, $15(15 \%)$ of respondents said culture, $5(5 \%)$ of respondents said peer pressure, $5(5 \%)$ of respondents said mass media while $22(22 \%)$ of respondents said all of the above. 
Table 17: Showing responses of the various means of carrying out sex education among adolescents.

\begin{tabular}{|c|c|c|}
\hline Means of sex education & Frequency & Percentage (\%) \\
\hline \hline Parents/guardians & 40 & 40 \\
\hline \hline School/teachers & 20 & 20 \\
\hline \hline Peers/friends & 5 & 5 \\
\hline \hline Religious bodies & 10 & 10 \\
\hline \hline All of the above & 25 & 25 \\
\hline Total & 100 & 100 \\
\hline
\end{tabular}

Source: Field survey, 2020

The above shows that, out of $100(100 \%)$ of respondents, $40(40 \%)$ of respondents said parents/guardians is a means of carrying out sex education, $20(20 \%)$ of respondents said schools/teachers is a means of carrying out sex education, $5(5 \%)$ of respondents said peer/friends is a means of carrying out sex education, $10(10 \%)$ of respondents said religious bodies is a means of carrying out sex education while $25(25 \%)$ of respondents said all of the above are means of carrying out sex education.

Table 18: Showing responses if sex education has an influence on abortion prevention.

\begin{tabular}{|c|c|c|}
\hline $\begin{array}{c}\text { Sex education and abortion } \\
\text { prevention }\end{array}$ & Frequency & Percentage (\%) \\
\hline \hline Yes & 94 & 94 \\
\hline \hline No & 6 & 6 \\
\hline \hline Total & 100 & 100 \\
\hline
\end{tabular}

Source: Field survey, 2020

The above table shows that, out of $100(100 \%)$ respondents, 94(94\%) of respondents said sex education have an influence on abortion prevention while $6(6 \%)$ of respondents said education does not have an influence on abortion prevention.

Table 19: Showing responses if sex education influence abortion prevention positively

\begin{tabular}{|c|c|c|}
\hline $\begin{array}{c}\text { Sex education influence } \\
\text { abortion prevention positively }\end{array}$ & Frequency & Percentage (\%) \\
\hline \hline Yes & 85 & 85 \\
\hline \hline No & 15 & 15 \\
\hline \hline Total & 100 & 100 \\
\hline
\end{tabular}

Source: Field survey, 2020

The table shows that out of 100(100\%) respondents, 83(83\%) of respondents said sex education influence abortion prevention positively while $15(15 \%)$ of respondents said sex education do not influence abortion prevention positively.

Table 20: Showing responses when education should be taught

\begin{tabular}{|c|c|c|}
\hline $\begin{array}{c}\text { When should sex education be } \\
\text { taught }\end{array}$ & Frequency & Percentage (\%) \\
\hline \hline At old age & 25 & 25 \\
\hline \hline At any age & 35 & 35 \\
\hline
\end{tabular}

\begin{tabular}{|c|c|c|}
\hline During adolescent & 40 & 40 \\
\hline \hline Should not be taught at all & 10 & 10 \\
\hline \hline Total & 100 & 100 \\
\hline
\end{tabular}

Source: Field survey, 2020

The above table shows that, out of $100(100 \%)$ respondents, $25(25 \%)$ of respondents said sex education should be taught at old age, $35(35 \%)$ of respondents said sex education should be taught at any age, 40(40\%) of respondents said sex education should be taught during adolescence while 10(10\%) of respondents said sex education should not be taught at all.

\section{ANSWERING RESEARCH QUESTIONS}

\section{Research Question 1}

What are the major factors responsible for lack of sex education among adolescents?

Table 16 showed that $50 \%$ of respondents said that family setting is the factor responsible for lack of sex education among adolescents, $3 \%$ said school is the factor responsible for lack of sex education among adolescents, $15 \%$ said culture is the factor responsible for lack of sex education among adolescents, $5 \%$ said peer pressure is the factor responsible for lack of sex education among adolescents, 5\% said mass media is responsible for lack of sex education among adolescents while $22 \%$ said all of the above are responsible for lack of sex education among adolescents.

It could be seen that, based on the above facts, family setting is the major factor responsible for lack of sex education among adolescents.

\section{Research Question 2}

What are the various means of carrying out sex education among adolescents?

Table 7 showed that $40 \%$ of respondents said parents/guardians is a means of carrying out sex education, $20 \%$ said schools/teachers is a means of carrying out sex education, 5\% said peers/friends is a means of carrying out sex education, $10 \%$ said religious bodies is a means of carrying out sex education while $25 \%$ said all of the above are means of carrying sex education.

Table 8 showed that, $17 \%$ of respondents said they were sex educated by parents/guardians, $18 \%$ said they were sex educated by school/teachers, $25 \%$ said they were sex educated by peers/friends, and $10 \%$ said they were sex educated by religious bodies while $30 \%$ said they were sex educated by mass media/internet.

It could be seen that, based on the above facts, parents/guardians is the main means of carrying out sex education among adolescents. 


\section{Research Question 3}

Do adolescents have the right information about sex and sexuality?

Table 13 showed that $11 \%$ of respondents said some of the sexual problems encountered by adolescents are teenage pregnancy and adolescent fatherhood, $8 \%$ of respondents said STIs are some of the sexual problems encountered by adolescents, $1 \%$ of respondents said abortion is one of the sexual problem encountered by adolescents while $80 \%$ of respondents said all of the above are sexual problems encountered by adolescents.

Table 14 showed that $11 \%$ of respondents said not engaging in illicit sexual activities is a way adolescents can prevent sexual problems, $8 \%$ of respondents said not engaging in criminal abortion is a way adolescents can prevent sexual problems, $60 \%$ of respondents said proper health education is a way adolescents can prevent sexual problems while $22 \%$ of respondents said all of the above are ways adolescents can prevent sexual problems.

Table 12 showed that $98 \%$ of respondents said sexual intercourse exposes one to sexual problems while $2 \%$ of respondent said sexual intercourse does not exposes one to sexual problems.

Table 9 showed that $3 \%$ of respondents have had sex while $97 \%$ have never had sex

This is in line with Kann, (2014), who carried out a comprehensive review of sex and HIV education programs, many participants in the program delayed or reduced sexual activity, reduced their number of sexual partners or increases condoms or contraceptive use.

Table 7 showed that $5 \%$ of respondents said sex education teaches children on how to have sex, $20 \%$ said sex education is providing information to adolescents on how to prevent STIs, $10 \%$ of respondents said sex education is providing information to adolescents on how to prevent pregnancy while $65 \%$ of respondents said sex education is to provide information to adolescents about sexual matters in order to impact knowledge in them for better understanding.

Based on the findings analyzed above, it could be seen that adolescents have the right information about sex and sexuality.

\section{Research Question 4}

What is the influence of sex education on abortion prevention among adolescents?

Table 18 showed that $94 \%$ of respondents said sex education has an influence on abortion prevention while $6 \%$ said sex education does not have an influence on abortion prevention.

Table 19 showed that $83 \%$ of respondents said that sex education influence abortion prevention positively while $15 \%$ said sex education do not influence abortion prevention positively.

Based on the data given above, it was concluded that sex education have an influence on abortion prevention.

\section{DISCUSSION}

\section{Objective 1}

To identify the major factors responsible for lack of sex education among adolescents.

Table 16 showed that $50 \%$ of respondents said that family setting is the factor responsible for lack of sex education among adolescents, 3\% said school is the factor responsible for lack of sex education among adolescents, $15 \%$ said culture is the factor responsible for lack of sex education among adolescents, $5 \%$ said peer pressure is the factor responsible for lack of sex education among adolescents, 5\% said mass media is responsible for lack of sex education among adolescents while $22 \%$ said all of the above are responsible for lack of sex education among adolescents.

In agreement with the highest percentage which is $50 \%$, the African population and Health Research Center (2020) opined that, in most traditional African societies, sexual and reproductive health topics are seldom discussed in family setting. Openly speaking about sexuality and sexual relationships is considered a taboo in many cultures. As a result, several nuclear family members never have conversations around these topics. Elliot (2010) also opined that parents are their children's best sex educators. However, he indicated that most parents' feels embarrassed while talking to their children about sex.

\section{Objective 2}

To identify the various means of carrying out sex education among adolescents.

Table 17 showed that $40 \%$ of respondents said parents/guardians is a means of carrying out sex education, $20 \%$ said schools/teachers is a means of carrying out sex education, $5 \%$ said peers/friends is a means of carrying out sex education, $10 \%$ said religious bodies is a means of carrying out sex education while $25 \%$ said all of the above are means of carrying sex education.

This confirms the United Nations Population Fund (2011) findings which states that, sex education may be taught informally such as when someone received information from a conversation with a parent. Daniels (2013), also opined that, throughout adolescents lives, they communicate with their parents which makes it easier to discuss about sex and it's effect.

Table 8 showed that, $17 \%$ of respondents said they were sex educated by parents/guardians, $18 \%$ said they were sex educated by school/teachers, $25 \%$ said they were sex educated by peers/friends, and $10 \%$ said they were sex educated by religious bodies while $30 \%$ said they were sex educated by 
mass media/internet. Adolescents rank the media with parents and peers as important sources of sexual information. They went further to say, this may be because the media are better at depicting the passion and positive possibilities of sex than its problems and consequences.

\section{Objective 3}

To identify if adolescents have the right information about sex and sexuality

Table 13 showed that $11 \%$ of respondents said some of the sexual problems encountered by adolescents are teenage pregnancy and adolescent fatherhood, $8 \%$ of respondents said STIs are some of the sexual problems encountered by adolescents, $1 \%$ of respondents said abortion is one of the sexual problem encountered by adolescents while $80 \%$ of respondents said all of the above are sexual problems encountered by adolescents.

Table 14 showed that $11 \%$ of respondents said not engaging in illicit sexual activities is a way adolescents can prevent sexual problems, $8 \%$ of respondents said not engaging in criminal abortion is a way adolescents can prevent sexual problems, $60 \%$ of respondents said proper health education is a way adolescents can prevent sexual problems while $22 \%$ of respondents said all of the above are ways adolescents can prevent sexual problems.

This agrees with Arpita (2011), who stated that, early sexual education helps adolescents understand sex and related issues such as sexually transmitted disease and unwanted pregnancy which might lead to abortion. In agreement, Walsh (2013), opined that, sex education helps adolescents to be aware of the risks and negative effects that can arise in the case of improper sexual behavior.

Table 12 showed that $98 \%$ of respondents said sexual intercourse exposes one to sexual problems while $2 \%$ of respondent said sexual intercourse does not exposes one to sexual problems.

This is in agreement with Walsh (2013), who stated that, sex education helps adolescents to be aware of the risks and negative effects that can arise in the case of improper sexual behaviour.

Table 9 showed that $3 \%$ of respondents have had sex while $97 \%$ have never had sex

This is in line with Kann, (2014), who carried out a comprehensive review of sex and HIV education programs, many participants in the program delayed or reduced sexual activity, reduced their number of sexual partners or increases condoms or contraceptive use.

Table 7 showed that $5 \%$ of respondents said sex education teaches children on how to have sex, $20 \%$ said sex education is providing information to adolescents on how to prevent STIs, $10 \%$ of respondents said sex education is providing information to adolescents on how to prevent pregnancy while
$65 \%$ of respondents said sex education is to provide information to adolescents about sexual matters in order to impact knowledge in them for better understanding.

This justifies the definition of sex education by the World Health Organization (2010), which states that, sexuality education is learning about the cognitive, emotional, social, interactive and physical aspects of sexuality. Sexuality education starts early in childhood and progresses through adolescence and adulthood. It aims at supporting and protecting sexual development. It gradually equips and empowers children and young people with information, skills and positive values to understand and enjoy their sexuality, have safe and fulfilling relationship for their own and other people's sexual health and well-being.

\section{Objective 4}

To identify the influence of sex education on abortion prevention among adolescents

Table 18 showed that $94 \%$ of respondents said sex education has an influence on abortion prevention while $6 \%$ said sex education does not have an influence on abortion prevention.

Table 19 showed that $83 \%$ of respondents said that sex education influence abortion prevention positively while $15 \%$ said sex education do not influence abortion prevention positively.

In agreement Pru (2014), opined that, better sex education has to mean that unwanted pregnancies and abortions will fall. Abortion will never be celebrated. In the same line, Arpita (2011), stated that early sexual education will help children understand sex and related issues such as sexuality transmitted diseases and pregnancy that might lead to unsafe abortion. Informed people make informed choice and this is where early sexuality education comes into play.

\section{CONCLUSION}

The result of this study shows that the adolescents in High Level, Makurdi Local Government Area of Benue State lack adequate knowledge of sex education on abortion prevention.

Information about sex and sexuality that the adolescents get is not enough to keep them safe from negative outcomes.

They were contradicting notions of when sex education should be commenced. Factors such as culture, family settings, peer pressure schools, mass media and some religious believes are responsible for lack of proper sex education of adolescents.

\section{RECOMMENDATIONS}

a. The following recommendations were made on the basis of the findings of this study. The Government should make policies that sex education should be part of school curriculums and taught extensively especially in secondary schools. 
b. The Government should finance and sponsor effective sex education programmes to make it available on mass media and make sure appropriate and correct information are passed across to the targeted audience which includes the positive and negative aspect of sex.

c. Seminars and programmes should be organized for the community with the community's full and active participation whereby parents/guardians are educated on the negative influence of lack of proper sex education of their children/wards might cause.

\section{REFERENCES}

[1] Anonymous. (2012). IPPF Framework for comprehensive sexuality education (CSE). London: IPPE. Available at http://www.ippf.org/sites/default/files/ippf-framework-forcomprehensive-sexuality-education.pdf.

[2] African Population and Health Research center, (2020). Lessons learned about life skill based education for HIV AIDs related risk and related discrimination.

[3] Arpita, D. E. (2011). Benefits of early sexual education only my health editorial team. www.onlymhealth.com.

[4] Daniels, U. (2013). Sex education that works. AVERT. Retrieved May. 2, 2020, from: www.avert.org.

[5] Elliot, D. (2010). Sex, youth, and sex education: A reference hand book Santa Barbara, CA: ABC-C40, Inc.

[6] Elliot, G.R, \& Feldman, S.S. (2013). Capturing the adolescent experience. In S.S Feldman \& G.R. Elliot (eds), at the threshold: The developing adolescent (pp.1-13). Cambridge: Harvard University Press.

[7] Kann, G. (2014). Lessons Learnesd about life skill-based education for HIV/AIDs related risk and related discrimination.
[8] Giatminh, F. (2012). The importance of sex education to the adolescents in the family $20^{\text {th }}$ May (2012) htt://ezinearticles.com/expea-felixobego.

[9] Grabber, J.A. (2016). Transition through adolescence: interpersonal domains and context. Mahwah, NJ.: Lawrence Erlbaum.

[10] Greenfield, P.M, Ker, H; \& Maynard, A (2015). Cultural pathways through universal development. Annual Review of Psychology, 54. 461-490.

[11] Hoai, G. (2012). Morality in sex education karenravue.com/2012/02/21/morality.

[12] Olatinka, F. (2011). Adolescents in Africa, Revealing the problems of teenagers in contemporary African Society. Ibadan: Hadassah Publishing.

[13] PPFA, (2012). Inside and out: comprehensive sexuality Education (CSE). London: PPFA. Available at http://www.ppfa.org/sites/default/files/ppfa-framework-forcomprehensive-sexuality-education.pdf.

[14] Pru, K. (2014)."Social and Cultural Determinants of Attitudes Toward Abortion: a Test of Reiss' Hypothesis". The Social Science Journal 46:493-505.

[15] Steinberg, L. (2014). Age of opportunity. Lessons from the new science of adolescence Boston, MA: Houghon Mifflin Harcourt.

[16] Walsh, F. (2013). Parental involvement in childhood education: Building effective school- family partnerships. Springer science \& Business Media

[17] WHO. (2011). Adolescent health. Retrieved from http://www.who.intopies/adolescent health/en/

[18] WHO Regional Office for Europe and BzgA. (2010). Standards for Sexuality Education in Europe. A framework for policy makers, educational and health authorities and specialists. Colgne: BzgA. Available at http://www.bzga-whocc.de/fileadmin/userupload/WHO.BzgA-standards-English.Pdf 